Int. J. Electrochem. Sci., 12 (2017) 4847 - 4855

\title{
Application of Gold Nanoparticle and Three-Dimensional Graphene Based Electrode for Sensitive Voltammetric Analysis of Luteolin
}

Zuorui Wen ${ }^{1}$, Xiaoyan $\mathrm{Li}^{1}$, Xueliang Niu ${ }^{1}$, Wenshu Zhao ${ }^{1}$,Yong Cheng ${ }^{2}$, Qianwen Ma ${ }^{1}$, Xiaobao Li ${ }^{1}$, Wei Sun ${ }^{1, *}$, Guangjiu Li ${ }^{2}$

${ }^{1}$ Key Laboratory of Tropical Medicinal Plant Chemistry of Ministry of Education, College of Chemistry and Chemical Engineering, Hainan Normal University, Haikou 571158, P R China,

${ }^{2}$ College of Chemistry and Molecular Engineering, Qingdao University of Science and Technology, Qingdao 266042, P. R. China

*E-mail: swyy26@ hotmail.com

doi: $10.20964 / 2017.06 .02$

Received: 20 February 2017 / Accepted: 29 March 2017 / Published: 12 May 2017

A nanocomposite composed of gold nanoparticle (Au) and three-dimensional graphene (3DGR) was electrodeposited on the surface of carbon ionic liquid electrode (CILE), which exhibited synergistic effects with improved electrochemical performance. Voltammetric behaviors of luteolin on $\mathrm{Au} / 3 \mathrm{DGR} / \mathrm{CILE}$ were evaluated with the electrochemical parameters calculated. At the selected conditions differential pulse voltammetric responses had good linear relationship with luteolin concentration from $5.0 \times 10^{-8}$ to $5.0 \times 10^{-5} \mathrm{~mol} \mathrm{~L}^{-1}$ and the detection limit was $7.59 \times 10^{-9} \mathrm{~mol} \mathrm{~L}^{-1}$. The Duyiwei soft capsules sample was successfully detected by the proposed method.

Keywords: Three-dimensional graphene, Gold nanoparticle, Luteolin, Carbon ionic liquid electrode, Electroanalysis

\section{$\underline{\text { FULL TEXT }}$}

(C) 2017 The Authors. Published by ESG (www.electrochemsci.org). This article is an open access article distributed under the terms and conditions of the Creative Commons Attribution license (http://creativecommons.org/licenses/by/4.0/). 